\title{
Proceeding Paper \\ Effect of Shungite Application on the Temperature Sensitivity of Allium cepa Respiration under Two Soil Water Regimes ${ }^{\dagger}$
}

\author{
Elena Ikkonen ${ }^{1, *}$, Svetlana Chazhengina ${ }^{2} \mathbb{D}$, Olga Bakhmet ${ }^{3}$ and Valeria Sidorova ${ }^{1}$ \\ 1 Institute of Biology, Karelian Research Center RAS, Puskinskaja, 11, 185610 Petrozavodsk, Russia; \\ val.sidorova@gmail.com \\ 2 Institute of Geology, Karelian Research Center RAS, Puskinskaja, 11, 185610 Petrozavodsk, Russia; \\ chazhengina@mail.ru \\ 3 Forest Research Institute, Karelian Research Center RAS, Puskinskaja, 11, 185610 Petrozavodsk, Russia; \\ bahmet@krc.karelia \\ * Correspondence: likkonen@gmail.com; Tel.: +7-911-0543-124 \\ † Presented at the 1st International Electronic Conference on Agronomy, 3-17 May 2021; Available online: \\ https://iecag2021.sciforum.net/.
}

Citation: Ikkonen, E.; Chazhengina,

S.; Bakhmet, O.; Sidorova, V. Effect of

Shungite Application on the

Temperature Sensitivity of Allium

cepa Respiration under Two Soil

Water Regimes. Biol. Life Sci. Forum

2022, 3, 9688. https://doi.org/

10.3390/IECAG2021-09688

Academic Editor: Youssef Rouphael

Published: 20 January 2022

Publisher's Note: MDPI stays neutral with regard to jurisdictional claims in published maps and institutional affiliations.

Copyright: (C) 2022 by the authors. Licensee MDPI, Basel, Switzerland. This article is an open access article distributed under the terms and conditions of the Creative Commons Attribution (CC BY) license (https:// creativecommons.org/licenses/by/ $4.0 /)$
Abstract: This study aimed to evaluate whether shungite application to Umbric Podzols may affect leaf and root mitochondrial respiratory pathways, and the leaf response to a temperature change. A pot culture experiment was conducted with Allium cepa L. seedlings, using soil shungite concentrations of $0,5,10$, and $20 \mathrm{~g} \mathrm{~kg}^{-1}$ and two soil water regimes: well-watered (WW) and drying-wetting (DW) cycles. The soil water deficit increased the total respiration $\left(V_{\mathrm{t}}\right)$ of onion leaves, but not roots, under low $\left(13^{\circ} \mathrm{C}\right)$ and high $\left(33^{\circ} \mathrm{C}\right)$ measurement temperatures. Shungite application affected leaf $V_{\mathrm{t}}$ only at $13^{\circ} \mathrm{C}$ : it increased the $V_{\mathrm{t}}$ rate under WW and decreased itunder DW. An increase in the measurement temperature to $33^{\circ} \mathrm{C}$ enhanced the sensitivity of leaf respiration to the inhibitor of the alternative respiratory pathway (salicylhydroxamic acid, SHAM). Shungite application increased the contribution of theSHAM-sensitive pathway to the leaf $V_{\mathrm{t}}$ rate under $\mathrm{WW}$, but not under the DW regime, regardless of the leaf temperature. In contrast to theSHAM-resistant pathway, the temperature sensitivity of the SHAM-sensitive rate decreased following the decrease in soil water availability. Shungite application increased the temperature sensitivity of both SHAM-sensitive and SHAM-resistant pathways under DW, and significantly decreased these parameters under WW. In summary, the decrease of temperature sensitivity of the alternative SHAM-sensitive respiratory pathway with a decrease of soil water availability or the shungite-related decrease of both SHAM-sensitive and SHAM-resistant leaf respiration may play an important role in enhancing the resistance of plant respiration to stress temperature.

Keywords: onion; rock powder; respiratory pathways; soil water deficit

\section{Introduction}

Rocks containing a multitude of nutrients have been proposed as a slow-release fertilizer that allows nutrients to remain in the top soil for a long time [1]. Therefore, the possibility of using rock powders as an alternative source of nutrients for agriculture practice has been widely discussed [2]. When initial nutrient levels in agricultural soils are low, the application of rock powders may improve not only the ion and cation exchange capacity [3] but also the physical properties of soils, as was shown for inorganic carbon [4].

Shungite rocks formed mainly on a silicate basis are carbon-bearing sedimentaryvolcanic rocks widely distributed in the Lake Onega area. The carbonaceous matter characterized by a globular fullerene-like molecular structure is one of the main components of the shungite [5]. Along with inorganic carbon, some macro- and micro-nutrients, such as $\mathrm{Si}, \mathrm{K}, \mathrm{Ca}, \mathrm{Mg}, \mathrm{Na}, \mathrm{Cu}$, and others, were found in the shungite rocks [5]. Since most of the nutrient elements are prevalent soil elements that beneficially affect the physiological state 
of plants, maintaining an adequate plant nutritional status may improve the physiological resistance of plants under stress situations, including stress temperatures [6] and soil water deficit [7].

Soils developed in the areas of shungite rocks have long attracted the attention of farmers and researchers [8]. Centuries-old human activity has revealed that the content of shungite in the soil can enhance the yield of agricultural crops, which could be associated with an improvement of the thermal regime or fertility of shungite soils [9]. Experimental evidence shows that shungite application can promote the plant growth rate, yield, and pathogen resistance for some species [10], but no information is available concerning the effects of shungite rocks on plant respiration, respiration pathways, and their temperature response.

It is well-documented that in agricultural practice, not only the low natural fertility of soils but also climatic factors such as stress temperature or an inadequate soil water regime have long been recognized as the main determining stress factors challenging current agricultural productivity. Along with photosynthesis, respiration is one of the main physiological processes responsible for plant growth and development. While the $\mathrm{CO}_{2}$ assimilation rate has been shown to be strongly suppressed by drought [11], the impact of the soil water deficit on plant respiration may be multidirectional: it decreases in the initial phase of water stress, and increases, as an acclimation mechanism, under lower soil water availability [12].

Plant respiratory metabolism is altered such that under stress conditions, other pathways, besides the cytochrome $c$ oxidase $(\mathrm{Cyt})$ pathway, are induced to provide alternative respiratory substrates to the respiratory processes $[13,14]$. Compelling evidence has recently demonstrated that alternative pathway respiration (Alt) associated with alternative oxidase activity provides flexibility in cellular energy and carbon metabolism, thus contributing to increased resistance of plants to stress conditions, including soil water deficit and low or high temperatures [13]. The drought-related increase of plant respiration rate described in [12] can be connected with the enhanced capacity of Alt, as was shown by Feng et al. [15]. However, the adjustment of respiratory metabolism, as a plant response to changesingrowth conditions, can be connected with increased electron partitioning to the Alt and decreased to the Cyt pathway, with the total leaf respiration not affected [16]. A recent study of the effect of both soil water regime and shungite application on physiological traits of onion seedlings showed that the first one has a much stronger effect on leaf respiration than the second [17]. Although theleaf respiration rate was not significantly affected by shungite application to the soilneither under sufficient norlow soil water availability, shungite improved the nutrient status of onion leaves and plant resistance to a water deficit [17]. This may be due to an impact of shungite on the activity of respiratory pathways, and/or change the partitioning between them, however, there has been no published evidence supporting this state. In this study, we hypothesized that the earlier reported positive effects of shungite rock on plant resistance to the soil water deficit could be connected with its impact on respiratory pathways.

Plant respiration is a temperature-sensitive process, with the temperature sensitivity being referred to as the temperature coefficient $\left(Q_{10}\right)$, defined as a proportional change in respiration rate per $10{ }^{\circ} \mathrm{C}$ change in temperature. The Alt and Cyt pathways have been shown to differ in their sensitivities to short-term changes in temperature [18]. It was proposed that the Alt pathway may maintain mitochondrial electron transport and protect against harmful reactive $\mathrm{O}_{2}$ generation in the cold due to this pathway being less temperature-sensitive (lower $\mathrm{Q}_{10}$ ) than theCyt pathway [19]. However, some studies found little difference in the $\mathrm{Q}_{10}$ values between the Alt and Cyt pathways [20], or a more sensitive Alt than Cyt pathway $[18,21]$. The shift of the temperature sensitivity of these respiratory pathways under changed conditions, for example, soil water or nutrient availability, can alter the partitioning between the pathways, and consequently, plant resistance to temperature stress. 
To estimate the pathways' activity at different temperatures, the respiratory inhibitorsare widely used in studies investigating the temperature sensitivity of the Alt and Cyt pathways [20,21]. Specifically, the Alt pathway is sensitive to salicylhydroxamic acid (SHAM), commonly used as an alternative oxide inhibitor. Although SHAM not only affects alternative oxide activity and can slightly modulate theCyt pathway, it is conventionally accepted that SHAM-sensitive respiration is a measure for the contribution of the Alt pathway to total respiration. The SHAM-resistant respiration corresponds to the sum of cytochrome-related electron transport and the residual non-mitochondrial respiration, which constitutes not more than $10 \%$ of the total respiration [22].

Our study investigates the effect of short-term changes in temperature on respiration in intact tissues of onion leaves. We examine whether the $\mathrm{Q}_{10}$ values of SHAM-resistant and SHAM-sensitive respiration differ and how shungite application to soil affects the temperature sensitivity of both SHAM-resistant and SHAM-sensitive respiratory pathways. Moreover, we establish the extent to which the shungite dependence on SHAM-resistant and SHAM-sensitive pathways is affected by a change in the soil water availability.

\section{Materials and Methods}

\subsection{Soil Substrate Preparation}

The soil used in this study was collected from the $0-30 \mathrm{~cm}$ topsoil layer of Umbric Podzols from the Korza valley, the northwest of Russia. Umbric Podzols, as stated earlier [23], are characterized by low natural fertility, thin layers $(10-20 \mathrm{~cm})$, and low content $(0.5-2.5 \%)$ of humus, as well as low $\mathrm{pH}(4-5)$. The soil was collected randomly, air-dried, and sieved with a $2 \mathrm{~mm}$ sieve. Shungite rock was taken from the Zazhoginodeposit (Karelia, Russia) and crushed to a size of $0.5 \mathrm{~mm}$. The shungite rock used inthis study contained, in the dry solid: $48.9 \%$ of $\mathrm{SiO}_{2}, 36.9 \%$ of $\mathrm{C}, 5.6 \%$ of $\mathrm{Al}_{2} \mathrm{O}_{3}, 2.4 \%$ of $\mathrm{F}_{2} \mathrm{O}_{3}, 1.8 \%$ of $\mathrm{K}_{2} \mathrm{O}, 0.95 \%$ of $\mathrm{MgO}, 0.84 \%$ of $\mathrm{S}$, and $0.14 \%$ of $\mathrm{CaO}$. Water extraction from shungite had $0.40 \mathrm{ppm} \mathrm{of} \mathrm{SO}_{4}{ }^{2-}$, 0.06 ppm of $\mathrm{Ca}^{+}, 0.03$ ppm of $\mathrm{Mg}^{2+}, 0.014$ ppm of $\mathrm{K}^{+}, 0.003 \mathrm{ppm}$ of $\mathrm{NH}_{4}^{+}, 0.0072 \mathrm{ppm}$ of $\mathrm{F}^{+}$, and $\mathrm{pH}$ was 4.3 . The entire volume of the dry soil was divided into four parts and mixed with shungite powder. Four concentrations of shungite powder were used in this experiment: $0,5,10$, and $20 \mathrm{~g}$ of shungite per $1 \mathrm{~kg}$ of dry soil, designated as $0 \mathrm{~S}, 5 \mathrm{~S}, 10 \mathrm{~S}$, and $20 \mathrm{~S}$, respectively. Before seed sowing, all soils were incubated under $21-23^{\circ} \mathrm{C}$ and $70-80 \%$ of the maximum soil water-holding capacity for 90 days.

\subsection{Plant Growth Conditions}

The soil substrates were placedinto plastic pots $(12 \mathrm{~cm}$ wide, $16 \mathrm{~cm}$ height). Before sowing, uniform seeds of onion (Allium cepa L., var. Sturon) were imbibed in water for $3 \mathrm{~h}$ and sown with 6 seeds per pot. All pots were subjected to a controlled climate chamber (VötschBioLine, Balingen, Germany) with conditions of $23 / 20{ }^{\circ} \mathrm{C}$ day/night temperature, $70 \%$ relative air humidity, a $16 \mathrm{~h}$ photoperiod, and $300 \mu \mathrm{mol} \mathrm{m} \mathrm{m}^{-2} \mathrm{~s}^{-1}$ of photosynthetic photon flux density. All pots were maintained well-watered for one week until seedlings were thinned to three seedlings per pot.

One week after sowing, the pots of the 0S, 5S, and $10 S$ treatments were randomly divided into two blocks and two watering treatments were applied: well-watered (WW) and drying-wetting cycles (DW). The WW seedlings were watered daily to maintain the soil moisture content at the level of about $80 \%$ of the water-holding capacity. The DW seedlings were watered once every five days, so from the beginning of the watering treatment before measurements, the onion plants were WW two times, on the 12th and 17th days after sowing. In this way, the completely randomized experimental design included four levels of shungite content in the soil (0S, 5S, 10S, and 20S) and two water regimes among the 0S, $5 S$, and $10 S$ treatments. For the $20 S$ treatment, only the WW regime was applied. Each treatment included eight pots. 


\subsection{Total and SHAM-Resistant Respiration Measurement}

In addition to the cytochrome $(\mathrm{Cyt})$ chain, plant mitochondria respiration is characterized by the presence of an alternative (Alt) pathway associated with the activity of alternative oxidase. Both pathways use electrons from the ubiquinone pool and support the cell energy balance, but unlike the Cyt pathway, the alternative pathway does not couple electron transportto the generation of a proton motive force for the synthesis of ATP. SHAM is used in studies of plant respiratory metabolism as a specific inhibitor of alternative oxidase. The sensitivity of respiration in intact plant tissues to SHAM provides indirect evidence for electron transport through the alternative oxidase-mediated pathway in the respiratory electron transport chain. Total respiration of leaves and roots and SHAM-respiration, which is resistant to salicylhydroxamic acid, were measured using a Clark-type oxygen electrode (Oxygraph Plus, Hansatech, Norfolk, UK) at $23^{\circ} \mathrm{C}$. Before the onset of respiration measurements, the plants were kept in the dark for $15 \mathrm{~min}$. A leaf sample (about $0.01 \mathrm{~g}$ of DW) was harvested with a razor blade, cut into small pieces, and suspended in $2 \mathrm{~mL}$ of air-saturated $100 \mathrm{mM}$ HEPES buffer ( $\mathrm{pH}$ 7.5) in the reaction vessel of the electrode unit. The $\mathrm{O}_{2}$ uptake rate was measured in the presence of SHAM, an agent commonly used as an inhibitor of alternative pathway respiration (Alt), or in the absence of SHAM. The roots were carefully washed to remove soil and each whole root system was divided into two halves, for the buffer with or without SHAM. The plant samples were kept in a buffer solution in darkness for approximately15 min until the process rate was stabilized, and then the $\mathrm{O}_{2}$ uptake rate was measured for $5 \mathrm{~min}$. The rate of oxygen uptake by plant samples in the SHAM-free buffer solution was defined as total respiration $\left(V_{\mathrm{t}}\right)$, and included both SHAM-resistant and SHAM-sensitive respiratory pathways. The $\mathrm{O}_{2}$ uptake rate in the SHAM-containing buffer was defined as SHAM-resistant respiration ( $\left.V_{\text {SHAM-res }}\right)$ and reflected mainly the Cyt pathway, and the difference between $V_{\mathrm{t}}$ and $V_{\text {SHAM-res }}$ was defined as SHAM-sensitive respiration $\left(V_{\text {SHAM-sens }}\right)$, and reflected the Alt pathway associated with alternative oxidase activity. By neglecting the influence of SHAM on Cyt pathway activity, the contribution of $V_{\mathrm{SHAM}}$-sens to the $V_{\mathrm{t}}$ rate (\%) was calculated as $V_{\text {SHAM-sens }} / V_{\mathrm{t}}$ ratio. While using this index, we realized possible limitations of the adopted approach. We assumed that SHAM-sensitive $\mathrm{O}_{2}$ uptake systems capable of mimicking the SHAM-inhibited respiration have a minor partitioning in the total oxygen uptake and are temperature-independent.

\subsection{Temperature Response of $\mathrm{O}_{2}$ Uptake Rates}

To determine the temperature response of $V_{\mathrm{t}}, V_{\text {SHAM-res, }}$ and $V_{\text {SHAM-res }}$ respiratory pathways of onion leaves, $\mathrm{O}_{2}$ uptake rates were measured ata buffer solution temperature of 13,23 , and $33{ }^{\circ} \mathrm{C}$. The required temperature was attained by connecting the reaction vessel with a water-bath thermostat (VEB MLW Prufgerate-Werk, GDR). The Clark-type oxygenelectrode calibration was carried out at each measurement temperature.

The temperature sensitivity of $\mathrm{O}_{2}$ uptake rates was evaluated using the temperature coefficient $\left(Q_{10}\right)$, which shows the proportional change in the respiration rate with a $10{ }^{\circ} \mathrm{C}$ increase in temperature. The $\mathrm{Q}_{10}$ values were determined by approximating the plots of respiration rates at different temperatures with a power function.

\subsection{Statistical Analysis}

For each treatment, the means \pm SE were determined with at least six replicates. To assess the significant difference between the treatments, the least significant difference (LSD) of the ANOVA was usedat the $p<0.05$ level. To ensure the normality and homogeneity of variances, the data were log-transformed if necessary. The effects of shungite concentration, water regime, and their interaction were analyzed using a two-way ANOVA, separately for each measuring temperature. All statistical tests were carried out with Statistica software (v. 8.0.550.0, StatSoft, Inc., Tulsa, OK, USA). When the differences between $\mathrm{O}_{2}$ uptake rates in the absence and presence of SHAM were statistically insignificant, the $V_{\text {SHAM-sens }}$ value was assumed to be zero. 


\section{Results}

\subsection{Total and SHAM-Resistant Respiration}

For the $0 S$ seedlings, a significant impact of the soil water deficit on total $\left(V_{\mathrm{t}}\right)$, but not SHAM-resistant $\left(V_{\text {SHAM-res }}\right)$, respiration was found under low $\left(13{ }^{\circ} \mathrm{C}\right)$ and high $\left(33^{\circ} \mathrm{C}\right)$ measurement temperatures (Figure $1 \mathrm{a}, \mathrm{c}$ ). The leaf $V_{\mathrm{t}}$ rate was higher in $0 \mathrm{~S}$ seedlings grown under the DW than the WW condition. On the contrary, at $23{ }^{\circ} \mathrm{C}$, no significant differences in the $V_{\mathrm{t}}$ rates of leaves and roots were found between $0 S$ seedlings grown under the DW and WW regimes, but $V_{\text {SHAM-res }}$ was higher in DW than WW leaves (Figure $1 \mathrm{~b}$ ). According to the two-way ANOVA, the $V_{\text {SHAM-res }}$ rate of both leaves and roots was significantly affected by soil water availability, but the effect of shungite application was not significant for both $V_{\mathrm{t}}$ and $V_{\text {SHAM-res }}$ rates at all measurement temperatures (Table 1 ). However, for certain conditions of temperature and soil water availability, this effect was significant. Therefore, shungite application decreased leaf $V_{\mathrm{t}}$ and $V_{\text {SHAM-res }}$ under DW and increased $V_{\mathrm{t}}$ under the $\mathrm{WW}$ regime at $13{ }^{\circ} \mathrm{C}$ (Figure 1a). Moreover, under the $\mathrm{WW}$ regime and at the temperatures of 23 and $33{ }^{\circ} \mathrm{C}$, seedlings grown in the soil containing shungite had lower $V_{\text {SHAM-res }}$ values than $0 S$ seedlings (Figure $1 \mathrm{~b}, \mathrm{c}$ ). For the roots, both $V_{\mathrm{t}}$ and $V_{\text {SHAM-res }}$ rates of $5 S$ and $10 S$ seedlings were lower under DW and higher under WW than those of OS seedlings, but these differences were not large enough to be statistically significant (Figure 1d).

(a)

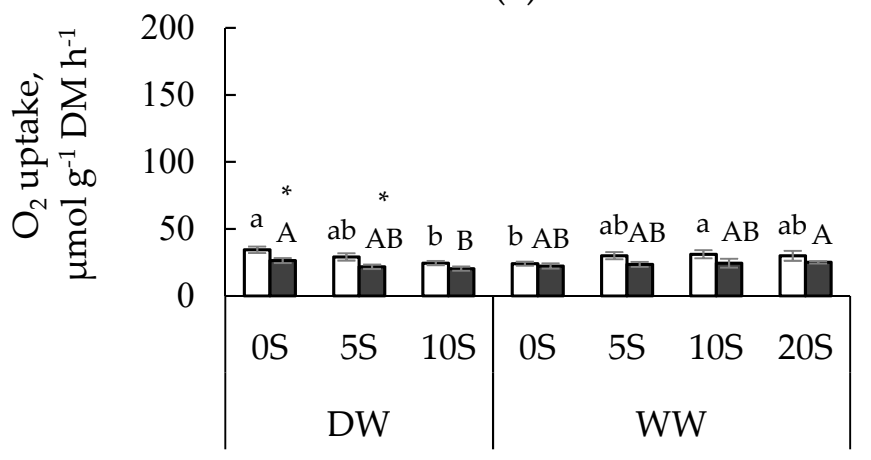

(c)

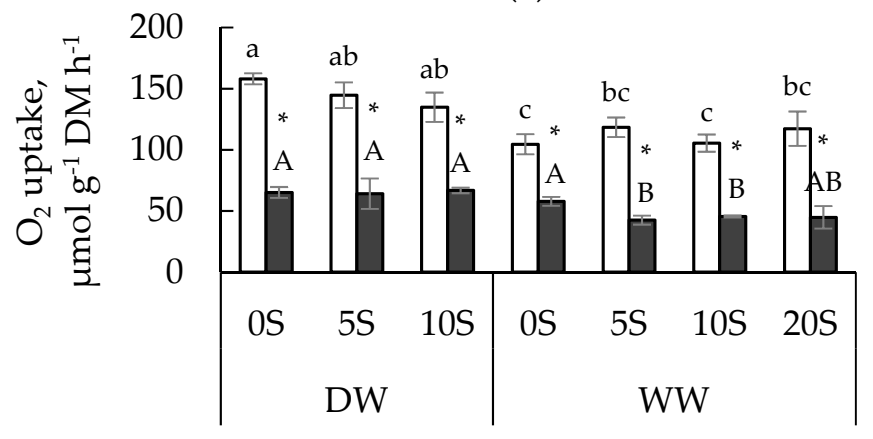

(b)

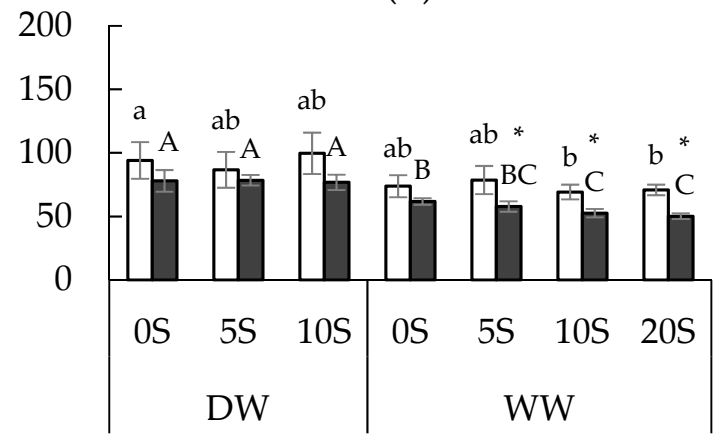

(d)

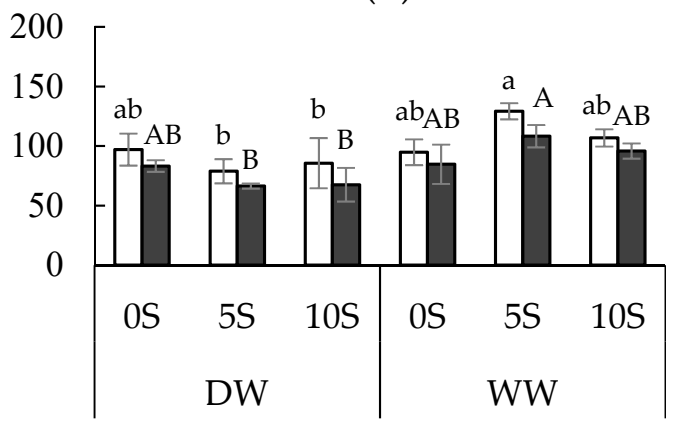

Figure 1. Total respiration (white bars) and SHAM-resistant respiration (black bars) for onion leaves $(\mathbf{a}-\mathbf{c})$ and roots (d) grown on the Umbric Podzols with shungite concentrations of 0 (0S), 5 (5S), 10 (10S), and 20 (20S) $\mathrm{g} \mathrm{kg}^{-1}$ under drying-wetting (DW) or well-watered (WW) regimes. During the measurements, the temperature was kept at 13 (a), 23 (b), or 33 (c) ${ }^{\circ} \mathrm{C}$. Different letters indicate significant differences: lower case isused for the white bars, capitals are used for the black bars.

* Indicates significant differences between $V_{\mathrm{t}}$ and $V_{\text {SHAM-res }}$ at $p<0.05$. 
Table 1. Statistical results ( $p$-value) of two-way ANOVA for the parameters shown in Figures 1 and 2.

\begin{tabular}{|c|c|c|c|}
\hline \multirow{2}{*}{ Variables } & \multicolumn{3}{|c|}{ Treatment Factor, Interaction } \\
\hline & Shungite & Water Regime & Shungite + Water Regime \\
\hline \multicolumn{4}{|l|}{ Leaves } \\
\hline \multicolumn{4}{|l|}{$13^{\circ} \mathrm{C}$} \\
\hline$V_{\mathrm{t}}$ & $0.233 \mathrm{~ns}$ & $0.194 \mathrm{~ns}$ & $0.052 \mathrm{~ns}$ \\
\hline$V_{\text {SHAM-res }}$ & $0.310 \mathrm{~ns}$ & $0.192 \mathrm{~ns}$ & $0.118 \mathrm{~ns}$ \\
\hline $\begin{array}{c}V_{\text {SHAM-sen }} / V_{\mathrm{t}} \\
23^{\circ} \mathrm{C}\end{array}$ & $<0.001 * * *$ & $0.702 \mathrm{~ns}$ & $0.047 *$ \\
\hline$V_{\mathrm{t}}$ & $0.606 \mathrm{~ns}$ & $0.093 \mathrm{~ns}$ & $0.420 \mathrm{~ns}$ \\
\hline$V_{\text {SHAM-res }}$ & $0.231 \mathrm{~ns}$ & $<0.001 * * *$ & $0.582 \mathrm{~ns}$ \\
\hline $\begin{array}{c}V_{\text {SHAM-sen }} / V_{\mathrm{t}} \\
33^{\circ} \mathrm{C}\end{array}$ & $0.049 *$ & $0.039 *$ & $0.030 *$ \\
\hline$V_{\mathrm{t}}$ & $0.551 \mathrm{~ns}$ & $0.093 \mathrm{~ns}$ & $0.394 \mathrm{~ns}$ \\
\hline$V_{\text {SHAM-res }}$ & $0.231 \mathrm{~ns}$ & $<0.001^{* * *}$ & $0.440 \mathrm{~ns}$ \\
\hline $\begin{array}{c}V_{\text {SHAM-sen }} / V_{\mathrm{t}} \\
\text { Roots } \\
23{ }^{\circ} \mathrm{C}\end{array}$ & $<0.001^{* * *}$ & $<0.001^{* * *}$ & $0.621 \mathrm{~ns}$ \\
\hline$V_{\mathrm{t}}$ & $0.788 \mathrm{~ns}$ & $0.042 *$ & $0.161 \mathrm{~ns}$ \\
\hline$V_{\text {SHAM-res }}$ & $0.902 \mathrm{~ns}$ & $0.022 *$ & $0.216 \mathrm{~ns}$ \\
\hline$V_{\text {SHAM-sen }} / V_{\mathrm{t}}$ & $0.405 \mathrm{~ns}$ & $0.108 \mathrm{~ns}$ & $0.621 \mathrm{~ns}$ \\
\hline
\end{tabular}

Asterisks denote significance levels: ${ }^{*} p<0.05,{ }^{* * *} p<0.001 ; \mathrm{ns}$, not significant. $V_{\mathrm{t}}$, total respiration; $V_{\mathrm{SHAM} \text {-res }}$ SHAM-resistant respiratory pathway; $V_{\text {SHAM-sen, }}$ SHAM-sensitive respiratory pathway.

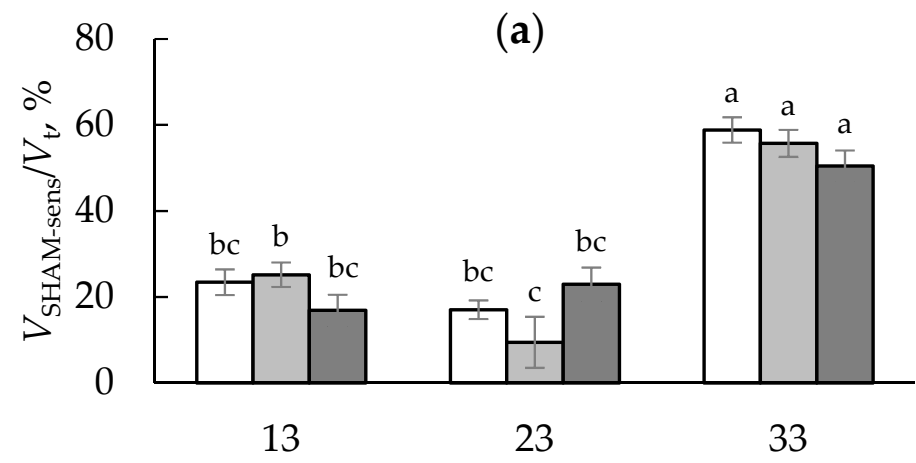

Leaf temperature, ${ }^{\circ} \mathrm{C}$

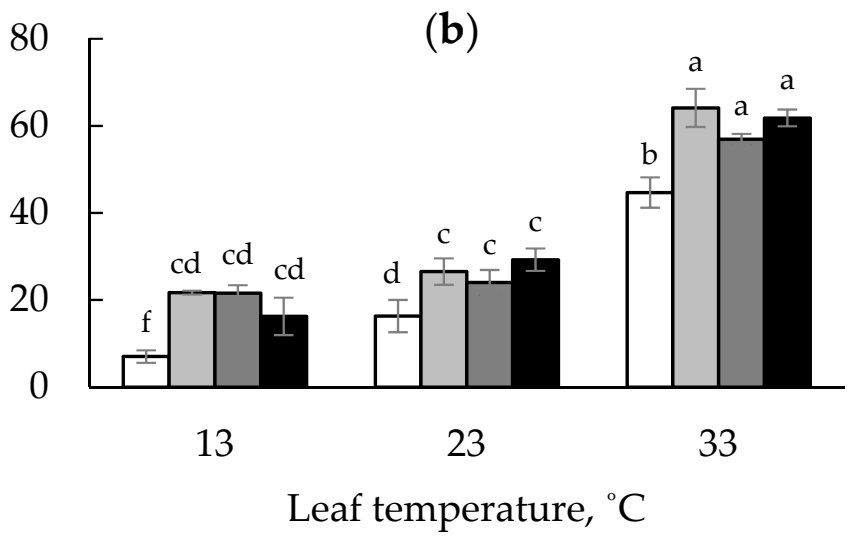

Figure 2. The $V_{\mathrm{SHAM} \text {-sen }} / V_{\mathrm{t}}$ ratio for leaf respiration of onion seedlings, grown on the Umbric Podzols with shungite concentrations of 0 (white bars), 5 (light gray bars), 10 (dark grey bars), and 20 (black bars) $\mathrm{g} \mathrm{kg}^{-1}$ under drying-wetting (a) or well-watered(b) regimes. Different letters indicate significant differences. 


\subsection{Ratio of SHAM-Sensitive to Total Respiration}

Onion leaf respiration was more sensitive to the inhibitor of the alternative pathway (SHAM) than root respiration, resulting in adecrease of leaf respiration when $\mathrm{O}_{2}$ uptake was measured in the presence of SHAM (Figure 1). However, this decrease was not significant for all combinations of the measurement temperature, soil water regime, and shungite treatment. Therefore, at $13{ }^{\circ} \mathrm{C}$, leaf respiration was more sensitive to SHAM for DW than WW seedlings, but at $23{ }^{\circ} \mathrm{C}$, on the contrary, it was more sensitive for WW than DW seedlings.

The increase of respiration sensitivity to SHAM reflects an increase in the contribution of theAlt respiratory pathway to total respiration. With the increase of the measurement temperature, the $V_{\text {SHAM-sens }} / V_{\mathrm{t}}$ ratio tended to increase (Figure 2). For the 0S leaves, $V_{\text {SHAM-sens }} / V_{\mathrm{t}}$ values were higher in DW than WW seedlings, regardless of the measurement temperature.

In contrast to the roots, for the leaves, the two-way ANOVA revealed a significant effect of both shungite application and soil water availability and their interaction on the $V_{\text {SHAM-sen }} / V_{\mathrm{t}}$ ratio (Table 1 ). In contrast to the DW cycle, shungite application significantly increased the leaf $V_{\mathrm{SHAM} \text {-sen }} / V_{\mathrm{t}}$ values for the seedlings grown under the WW regime at all measurement temperatures, regardless of the soil shungite content (Figure 2).

\subsection{Respiratory Coefficient $\left(Q_{10}\right)$}

The $\mathrm{Q}_{10}$ values of leaf $V_{\mathrm{t}}$ and $V_{\text {SHAM-res }}$ did not differ significantly between the $0 S$ seedlings grown under DW and WW regimes, but $\mathrm{Q}_{10}$ of $V_{\text {SHAM-sens }}$ strongly decreased following the decrease in soil water availability (Figure 3). Regardless of the shungite treatment and soil water regime, the $\mathrm{Q}_{10}$ valueswere higher for the $V_{\text {SHAM-sens }}$ than $V_{\mathrm{t}}$ and $V_{\text {SHAM-res }}$ rates. The opposite effect of shungite application on therespiratory coefficient was found for seedlings grown under DW and WW regimes. While under the DW condition, shungite application increased $\mathrm{Q}_{10}$ of both $V_{\text {SHAM-res }}$ and $V_{\text {SHAM-sens, }}$ increasing $V_{\mathrm{t}}$, under the WW regime, shungite significantly decreased therespiratory coefficient of both respiratory pathways.

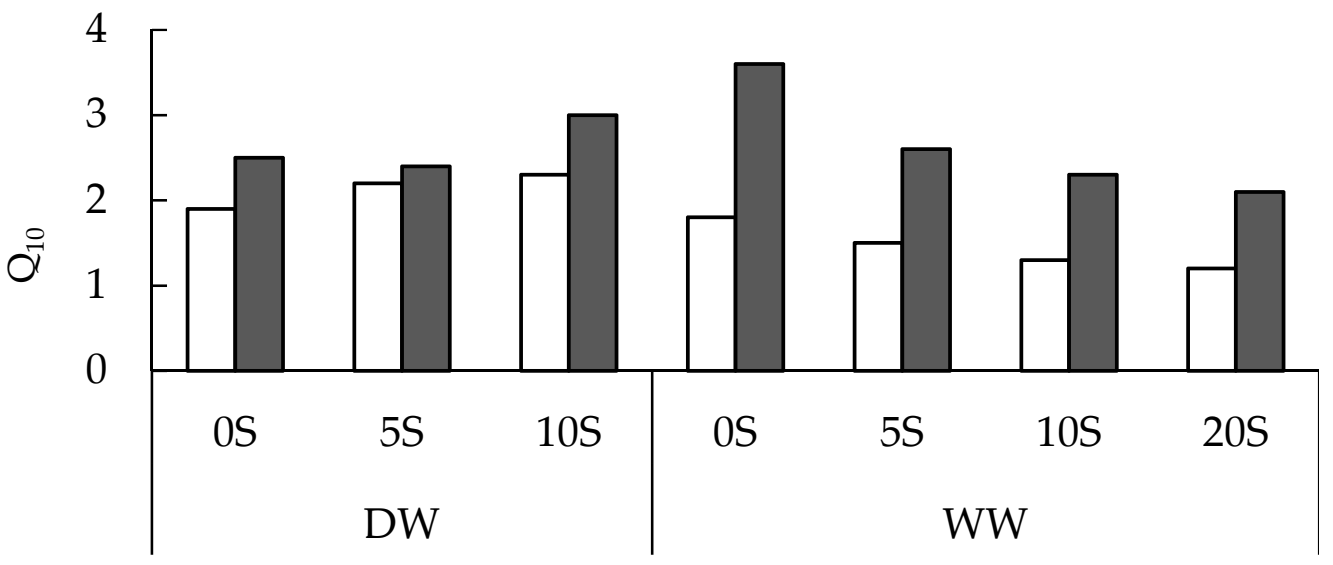

Figure 3. Temperature sensitivity $\left(\mathrm{Q}_{10}\right)$ of the SHAM-resistant (white bars) and SHAM-sensitive (black bars) leaf respiration of onion seedlings growing on the Umbric Podzols, with shungite concentrations of 0 (0S), 5 (5S), 10 (10S), and 20 (20S) $\mathrm{g} \mathrm{kg}^{-1}$ under drying-wetting (DW) or wellwatered $(\mathrm{WW})$ regimes.

\section{Discussion}

This study was aimed at assessing whether shungite application to soil has the potential to alter the leaf and root respiration rate and temperature sensitivity $\left(\mathrm{Q}_{10}\right)$ of SHAMresistant respiration, mainly reflecting the Cyt pathway, and SHAM-sensitive respiration, reflecting the Alt pathway, using onion seedlings as a model. Therefore, we quantified the effects of soil water availability on the respiratory $Q_{10}$ value to understand whether its 
response to shungite application depends on the soil water conditions. The onion leaves and roots showed a different response to the soil water deficit (Figure 1). While among all treatments the total root respiration tended to decrease, leaf respiration increased during water limitations. Moreover, in contrast to the roots, onion leaves were sensitive to both shungite application and SHAM.

The positive role of the Alt pathway in plant metabolism under stress conditions has been widely discussed [13-16] due to its ability to stabilize the reduction level of the ubiquinone pool and prevent the production of excessive amounts of reactive oxygen species [24]. Soil water deficit and low temperature are some of the important factors limiting crop yield. We have shown that a soil water deficit can stimulate onion leaf respiration mainly due to an increased rate of SHAM-sensitive respiration (Figure 1). While our results (Figure 2) support previous findings that the contribution of the Alt pathway to total respiration increases following decreased water availability [25], for onion leaves, this was only found at the low and high measurement temperatures. However, at the optimal temperature, the increase of total leaf respiration in response to water limitations was associated with the increase of SHAM-resistant respiration. Thus, different mitochondrial respiratory pathways may be involved inplant respiration acclimation to soil water deficits, with the pathway contribution depending on environmental conditions, particularly temperature.

Our finding (Figure 3) that the temperature sensitivity of SHAM-sensitive respiration is higher than the sensitivity to short-term changes in temperature for SHAM-resistant respiration is consistent with earlier studies [20,21]. It is known that plant respiratory $\mathrm{Q}_{10}$ values are affected by the growth environment and may vary significantly [20]. While the temperature sensitivity of respiration has been mainly studied at the total respiration level, the results of this study highlight the variability of both SHAM-resistant and SHAM-sensitive respiratory pathways. The results have shown that the $\mathrm{Q}_{10}$ values of the respiratory pathways of onion leaves studied herecan be altered by changes in soil water availability, as well as shungite application to the soil. Slot et al. [26] found that the $\mathrm{Q}_{10}$ values of total dark respiration of Geumurbanumleaves, as well as the respiration rate, increase in response to the decrease of water availability. For onion leaves, our results have shown the same effect of a water deficit on total respiration, although in our study, the sensitivity of total respiration to short-term temperature changes was not strongly affected by the soil water regime (data not shown). However, the water deficit slightly increased the $\mathrm{Q}_{10}$ value of SHAM-resistant respiration and significantly decreased this parameter of the SHAM-sensitive pathway, as was found for seedlings grown on the soil without shungite (Figure 3, 0S treatment).

The effect of shungite application on the temperature sensitivity of SHAM-resistant and SHAM-sensitive respiration of onion leaves was strongly dependent on the soil water availability. While the shungite application increased the $\mathrm{Q}_{10}$ values of both SHAMresistant and SHAM-sensitive respiration during the water deficit, shungite decreased these values under the condition of sufficient water availability. The cause of the variability in respiratory $\mathrm{Q}_{10}$ values has not yet been well-established, especially for the respiratory pathways. The temperature sensitivity of respiratory flux has been shown to be variable, depending on the level of ubiquinone reduction, the degree of adenylate control of the Cyt pathway [20], and/or the availability of respiratory substrates [27]. The $\mathrm{Q}_{10}$ values of $\mathrm{O}_{2}$ consumption can increase following a substrate availability increase [27], an increase of ubiquinone reduction, and an increase of the activation state of the Alt pathway [20]. A recent study [17] showed that the shungite application to the soil can alter nutrient concentrations of onion seedlings. Depending on the soil water regime, shungite can increase the plant content of potassium, manganese, zinc, and nickel, thus affecting some physiological traits of onion seedlings [17]. It can be suggested that the shungite-related change of $Q_{10}$ values of SHAM-resistant and SHAM-sensitive respiration might be partly controlled by the nutrient element contents. 
The ability of plants to enhance electron transport through the Alt pathway in cold temperatures $[13,14,16,28]$ could be due to the Alt pathway being less temperature-sensitive than the Cyt pathway [29]. The results of this study are consistent with some earlier reports that have shown that the sensitivity of the Alt pathway to the short-term temperature changes may not be lower than that of the Cyt pathway $[20,21,28]$. For the OS onion leaves grown under the condition of sufficient water availability, the higher $\mathrm{Q}_{10}$ value of the Alt pathway than the Cyt pathway was connected with the lowest contribution of SHAMsensitive respiration to total respiration at a low measurement temperature (Figure 2). These data confirm the finding of Armstrong et al. [21] that during the short-term temperature drop, the activity of electron transport through the Alt pathway declines and does not play an important role in maintaining flux through the mitochondrial electron transport. However, both shungite application at sufficient water availability and the soil water deficit may decrease the sensitivity of the SHAM-sensitive pathway to the short-term temperature change. This allows the Alt pathway to be more involved in the electron transport process, and in doing so reduces the production of reactive $\mathrm{O}_{2}$ species. Under the condition of the well-watered regime, the shungite application decreased the temperature sensitivity of not only the SHAM-sensitive but also theSHAM-resistant pathway (Figure 3). The decreaseof the temperature sensitivity of respiratory pathways can help to maintain mitochondrial electron transport and the cell redoxstate during temperature drops, and thus the plant resistance to low temperatures.

\section{Conclusions}

The data demonstrate that both Cyt and Alt respiratory pathways of $A$. cepa leaves and their sensitivity to short-term temperature changes can be dynamic when plants are subjected to the contrasting conditions of soil water availability or shungite content. For plants grown without shungite, the water deficit decreased the $Q_{10}$ values of Cyt but not Alt respiration. The response of the temperature sensitivity of the pathways to shungite application depends on the water availability. The shungite-related decrease of both Cyt and Alt pathways may play an important role in enhancing the resistance of plant respiration to the temperature drop. Although shungite rocks are widely used in various industries, their use in agriculture is still being studied. The obtained results showed that the shungite rocks might have the potential for agricultural application, though further investigations including field studies are required.

Supplementary Materials: The poster presentation can be downloaded at: https:/ /www.mdpi.com/ article/10.3390/IECAG2021-09688/s1.

Author Contributions: E.I. designed and performed the experiments, analyzed the data, and wrote the paper; S.C. wrote the paper; O.B. and V.S. conceived the experiments. All authors have read and agreed to the published version of the manuscript.

Funding: This research was funded by the project of the Ministry of Science and Higher Education of the Russian Federation, grant number FMEN-2022-0004, and partly by the Russian Foundation for Basic Research, grant number 19-29-05174.

Institutional Review Board Statement: Not applicable.

Informed Consent Statement: Not applicable.

Data Availability Statement: Not applicable.

Acknowledgments: Experimental facilities for this study were offered by the Core Facility of the Karelian Research Centre of the Russian Academy of Sciences.

Conflicts of Interest: The authors declare no conflict of interest. The founding sponsors had no role in the design of the study; in the collection, analyses, or interpretation of data; in the writing of the manuscript, orin the decision to publish the results. 


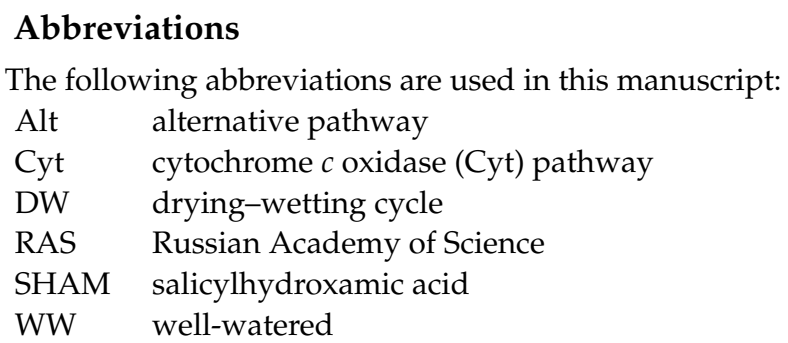

\section{References}

1. Coroneos, C.; Hinsinger, P.; Gilkes, R.J. Granite powder as a source of potassium for plants: A glasshouse bioassay comparing two pasture species. Fertil. Res. 1996, 45, 143-152. [CrossRef]

2. Van Straaten, P. Farming with rocks and minerals: Challenges and opportunities. Anais da Academia Brasileira de Ciencias 2006, 78, 731-747. [CrossRef]

3. Blum, W.E.H.; Herbinger, B.; Mentler, A.; Ottner, F.; Pollack, M.; Unger, E.; Wenzel, W.W. The use of rock powders in agriculture. II. Efficiency of rock powders for soil amelioration. ZeitschriftfürPflanzenernährung und Bodenkunde 1989, 152, 427-430. [CrossRef]

4. Krasilnikov, P.V. Stable carbon compounds in soils: Their origin and functions. Eurasian Soil Sci. 2015, 48, 997-1008. [CrossRef]

5. Buseck, P.R.; Galdobina, L.P.; Kovalevski, V.V.; Rozhkova, N.N.; Valley, J.W.; Zaidenberg, A.Z. Shungites: The C-rich rocks of Karelia, Russia. Can. Mineral. 1997, 35, 1363-1378.

6. Waraich, E.A.; Ahmad, R.; Halim, A.; Aziz, T. Alleviation of temperature stress by nutrient management in crop plants: A review. J. Soil Sci. Plant Nutr. 2012, 12, 221-244. [CrossRef]

7. Morales, F.; Pavlovič, A.; Abadia, A.; Abadia, J. Photosynthesis in Poor Nutrient Soils, in Compacted Soils, and under Drought. In The Leaf: A Platform for Performing Photosynthesis, Advances in Photosynthesis and Respiration; Adams, W.W., III, Terashima, I., Eds.; Springer: Cham, Switzerland, 2018; Volume 44, pp. 371-399.

8. Filippov, M.M.; Deynes, Y.E. History of discovery, study and practical use of Shunga shungite deposit. Proc. Fersman Sci. Sess. KarRC RAS 2018, 15, 37-40. (In Russian)

9. Toikka, M.A.; Kekkonen, A.P. Shungite as a local fertilizer. Sci. Lett. Karelian-Finn. Univ. 1946, 1, 214-268. (In Russian)

10. Timeyko, L.V.; Kuznetsova, L.A. The use of waste processing mineral shungite in potato of Karelia. Sci. Turn Millenn. 2010, 9 , 64-65. (In Russian)

11. Mahouachi, J.; Socorro, A.R.; Talon, M. Responses of papaya seedlings (Carica papaya L.) to water stress and re-hydration: Growth, photosynthesis and mineral nutrient imbalance. Plant Soil 2006, 281, 137-146. [CrossRef]

12. Flexas, J.; Galmes, J.; Ribas-Carbo, M.; Medrano, H. The effect of water stress on plant respiration. In Plant Respiration; Lambers, H., Ribas-Carbo, M., Eds.; Springer: Dordrecht, The Netherlands, 2005; pp. 85-94.

13. Vanlerberghe, G.C. Alternative oxidase: A mitochondrial respiratory pathway to maintain metabolic and signaling homeostasis during abiotic and biotic stress in plants. Int. J. Mol. Sci. 2013, 14, 6805-6847. [CrossRef]

14. Grabel'nykh, O.I.; Borovik, O.A.; Tauson, E.L.; Pobezhimova, T.P.; Katyshev, A.I.; Pavlovskaya, N.S.; Koroleva, N.A.; Lyubushkina, I.V.; Bashmakov, V.Y.; Popov, V.N.; et al. Mitochondrial energy-dissipating systems (alternative oxidase, uncoupling proteins, and external NADH dehydrogenase) are involved in development of frost-resistance of winter wheat seedlings. Biochemistry 2014, 79, 506-519. [CrossRef]

15. Feng, H.; Duan, J.; Li, H.; Liang, H.; Li, X.; Han, N. Alternative Respiratory Pathway under Drought is Partially Mediated by Hydrogen Peroxide and Contributes to Antioxidant Protection in Wheat Leaves. Plant Prod. Sci. 2008, 11, 59-66. [CrossRef]

16. Ribas-Carbo, M.; Aroca, R.; González-Meler, M.A.; Irigoyen, J.J.; Sánchez-Díaz, M. The Electron Partitioning between the Cytochrome and Alternative Respiratory Pathways during Chilling Recovery in Two Cultivars of Maize Differing in Chilling Sensitivity. Plant Physiol. 2000, 122, 199-204. [CrossRef]

17. Ikkonen, E.; Chazhengina, S.; Butilkina, M.; Sidorova, V. Physiological response of onion (Allium cepa L.) seedlings to shungite application under two soil water regimes. Acta Physiol. Plant. 2021, 43, 76-89. [CrossRef]

18. Gonzàlez-Meler, M.A.; Ribas-Carbo, M.; Giles, L.; Siedow, J.N. The Effect of Growth and Measurement Temperature on the Activity of the Alternative Respiratory Pathway. Plant Physiol. 1999, 120, 765-772. [CrossRef] [PubMed]

19. Stewart, C.R.; Martin, B.; Reding, L.; Cerwick, S. Respiration and Alternative Oxidase in Corn Seedling Tissues during Germination at Different Temperatures. Plant Physiol. 1990, 92, 755-760. [CrossRef] [PubMed]

20. Atkin, O.K.; Zhang, Q.; Wiskich, J.T. Effect of temperature on rates of alternative and cytochrome pathway respiration and their relationship with the redox poise of the quinine pool. Plant Physiol. 2002, 128, 212-222. [CrossRef]

21. Armstrong, A.F.; Badger, M.R.; Day, D.A.; Barthet, M.M.; Smith, P.M.C.; Millar, A.H.; Whelan, J.; Atkin, O.W. Dynamic changes in the mitochondrial electron transport chain underpinning cold acclimation of leaf respiration. Plant Cell Environ. 2008, 31, 1156-1169. [CrossRef] [PubMed]

22. Garmash, E.V.; Grabelnych, O.I.; Velegzhaniniv, I.O.; Borovik, O.A.; Dalke, I.V.; Voinikov, V.K.; Golovko, T.K. Light regulation of mitochondrial alternative oxidase pathway during greening of etiolated wheat seedlings. J. Plant Physiol. 2015, 174, 75-84. [CrossRef] 
23. Kuznetsova, I.V.; Utkaeva, V.F.; Bondarev, A.G. Assessment of changes in the physical properties of plowed loamy soddy-podzolic soils in the nonchernozemic zone of European Russia under the impact of anthropogenic loads. Eurasian Soil Sci. 2009, 42, 137-146. [CrossRef]

24. Florez-Sarasa, I.; Fernie, A.R.; Gupta, K.J. Does the alternative respiratory pathway offer protection against the adverse effects resulting from climate change? J. Exp. Bot. 2020, 71, 465-469. [CrossRef] [PubMed]

25. Vanlerberghe, G.S.; Martyn, G.D.; Dahal, K. Alternative oxidase: A respiratory electron transport chain pathway essential for maintaining photosynthetic performance during drought stress. Physiol. Plant. 2016, 157, 322-337. [CrossRef] [PubMed]

26. Slot, M.; Zaragoza-Castells, J.; Atkin, A.O. Transient shade and drought have divergent impacts on the temperature sensitivity of dark respiration in leaves of Geumurbanum. Funct. Plant Biol. 2008, 35, 1135-1146. [CrossRef] [PubMed]

27. Covey-Crump, E.M.; Attwood, R.G.; Atkin, O.K. Regulation of root respiration in two species of Plantago that differ in relative growth rate: The effect of short- and long-term changes in temperature. Plant Cell Environ. 2002, 25, 1501-1513. [CrossRef]

28. Ikkonen, E.N.; Grabelnykh, O.I.; Sherudilo, E.G.; Shibaeva, T.G. Salicylhydroxamic Acid-Resistant and Sensitive Components of Respiration in Chilling-Sensitive Plants Subjected to a Daily Short-Term Temperature Drop. Russ. J. Plant Physiol. 2020, 67, 60-67. [CrossRef]

29. Kiener, C.M.; Bramlage, W.J. Temperature effects on the activity of the alternative respiratory pathway in chill-sensitive Cucumis sativus. Plant Physiol. 1981, 68, 1474-1478. [CrossRef] 